\title{
Frontal-Brainstem Pathways Mediating Placebo Effects on Social Rejection
}

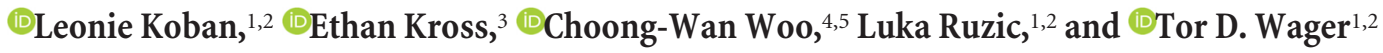 \\ ${ }^{1}$ Institute of Cognitive Science and ${ }^{2}$ Department of Psychology and Neuroscience, University of Colorado, Boulder, Colorado 80309, ${ }^{3}$ Department of \\ Psychology, University of Michigan, Ann Arbor, Michigan 48109, and ${ }^{4}$ Center for Neuroscience Imaging Research, Institute for Basic Science and \\ ${ }^{5}$ Department of Biomedical Engineering, Sungkyunkwan University, Suwon 16419, Republic of Korea
}

Placebo treatments can strongly affect clinical outcomes, but research on how they shape other life experiences and emotional well-being is in its infancy. We used fMRI in humans to examine placebo effects on a particularly impactful life experience, social pain elicited by a recent romantic rejection. We compared these effects with placebo effects on physical (heat) pain, which are thought to depend on pathways connecting prefrontal cortex and periaqueductal gray (PAG). Placebo treatment, compared with control, reduced both social and physical pain, and increased activity in the dorsolateral prefrontal cortex (dlPFC) in both modalities. Placebo further altered the relationship between affect and both dIPFC and PAG activity during social pain, and effects on behavior were mediated by a pathway connecting dlPFC to the PAG, building on recent work implicating opioidergic PAG activity in the regulation of social pain. These findings suggest that placebo treatments reduce emotional distress by altering affective representations in frontal-brainstem systems.

Key words: emotion regulation; nociception; opioid; placebo; resilience; social

\section{Significance Statement}

Placebo effects are improvements due to expectations and the socio-medical context in which treatment takes place. Whereas they have been extensively studied in the context of somatic conditions such as pain, much less is known of how treatment expectations shape the emotional experience of other important stressors and life events. Here, we use brain imaging to show that placebo treatment reduces the painful feelings associated with a recent romantic rejection by recruiting a prefrontal-brainstem network and by shifting the relationship between brain activity and affect. Our findings suggest that this brain network may be important for nonspecific treatment effects across a wide range of therapeutic approaches and mental health conditions.

\section{Introduction}

Placebo effects are improvements in symptoms caused by treatment cues, expectations, and the psychosocial context in which treatment takes place. Placebo effects are especially important in the treatment of pain and depression, although their effects extend to a large number of other conditions as well (Kirsch and Sapirstein, 1998; Benedetti, 2008; Weimer et al., 2015). Placebo effects tap into endogenous brain processes that promote healing; thus, understanding them can help us understand the central mechanisms by which therapies may work across disorders (Price

\footnotetext{
Received Aug. 20, 2016; revised Feb. 21, 2017; accepted Feb. 25, 2017.

Author contributions: E.K. and T.D.W. designed research; E.K. and T.D.W. performed research; C.-W.W., L.R., and T.D.W. contributed unpublished reagents/analytic tools; L.K. analyzed data; L.K. and T.D.W. wrote the paper.

This work was supported by a Swiss National Science Foundation Fellowship PBGEP1-142252 to L.K. and National Institutes of Health Grants R01DA035484 and R01MH076136 to T.D.W.

The authors declare no competing financial interests.

Correspondence should be addressed to Dr. Leonie Koban, University of Colorado, Muenzinger D244, Boulder, CO 80309-0345. E-mail: leonie.koban@colorado.edu.

DOI:10.1523/JNEUROSCI.2658-16.2017

Copyright $\odot 2017$ the authors $\quad 0270-6474 / 17 / 373621-11 \$ 15.00 / 0$
}

et al., 2008; Wager and Fields, 2013). Yet, although placebo effects on physical pain have been relatively well studied, they have seldom been compared with placebo effects on other affective processes and clinical disorders.

A literature on the neurophysiological mechanisms of placebo effects on affective states is emerging, with recent studies on depression (Leuchter et al., 2002; Mayberg et al., 2002; Peciña et al., 2015), negative emotion (Petrovic et al., 2005; Schienle et al., 2014; Meyer et al., 2015), and pleasure and value (Plassmann et al., 2008; Ellingsen et al., 2013). This literature suggests potential common mechanisms across disorders, based on placebo-induced reductions in stress and negative affect, and engagement in positive appraisal (Flaten et al., 2011; Wager and Atlas, 2015). Recent findings suggest transfer from placebo effects on pain to reductions in negative emotional states (Zhang and Luo, 2009; Rütgen et al., 2015). Yet, placebo effects on many of the affective processes central to the development of psychopathology have not been studied. Among these, the "pain" of social rejection is particularly important and among the most aversive events humans experience. It is long-lasting (Chen et al., 2008) and associated with depression, substance use, 
increased stress-induced inflammation, and other negative health outcomes (Eisenberger and Cole, 2012; Murphy et al., 2015). Individuals who experience a targeted romantic rejection are 20 times more likely to develop depression than the general population (Slavich et al., 2010). Rejection may also be particularly amenable to interventions that target appraisal processes (Kross et al., 2007), making it an important process to study at the brain and psychological levels. The present study compared the brain mechanisms of placebo effects on social rejection-related distress ("social pain") with those on heat pain (placebo analgesia).

Neuroimaging studies of placebo effects on physical pain suggest that activation of prefrontal areas, including dorsolateral (dlPFC), rostral anterior cingulate cortex (rACC), orbitofrontal (OFC), and ventromedial prefrontal cortex (vmPFC), influences pain by activating descending pain regulatory pathways in the brainstem, especially opioidergic mechanisms in the periaqueductal gray (PAG) (Vogt et al., 1993; Benedetti et al., 1999; Petrovic et al., 2002; Bingel et al., 2007; Wager et al., 2007; Scott et al., 2008; Eippert et al., 2009; Wager and Atlas, 2015). Prefrontal-PAG pathways are important in animal models of pain control as well. PAG pathways mediate multiple types of behavioral context effect on pain (Fields et al., 2006), and prefrontal stimulation in rats evokes PAG- and opioid-mediated analgesia (Zhang et al., 1997).

Effects of placebo treatment on social rejection-related pain have not been studied, and no studies have directly compared them with placebo effects on physical pain, although previous work has implicated the opioid system in social pain (Panksepp et al., 1980; Way et al., 2009). A recent PET study (Hsu et al., 2013) suggests that increased opioidergic activation of limbic and brainstem areas during social rejection is associated with resilience, implying opioid involvement in the endogenous regulation of rejection and other negative emotions (Zubieta et al., 2003; Ribeiro et al., 2005).

We therefore hypothesized that the PAG might be recruited by frontal regions that represent placebo-induced beliefs and expectations, especially the dlPFC and the vmPFC/OFC/rACC (Fig. $1 A)$. We predicted that activation of these prefrontal and brainstem regions would mediate placebo responses to social and physical pain.

\section{Materials and Methods}

\section{Participants}

Forty right-handed participants ( 19 male, 21 female, mean age 20.8 years, range 18-28 years) who experienced an unwanted breakup of their romantic relationship within the past 6 months $($ mean $=2.74$ months, $\mathrm{SD}=1.7$ months) were recruited for the experiment (baseline data reported in Kross et al., 2011). All participants were screened for neurological and psychiatric illnesses, psychoactive medication, and MRI exclusion criteria. Experimental groups (Placebo vs Control) were matched with respect to demographic variables, clinical

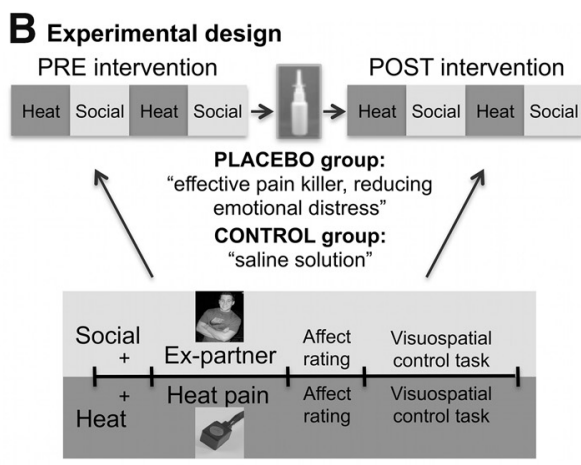

D Multilevel mediation approach
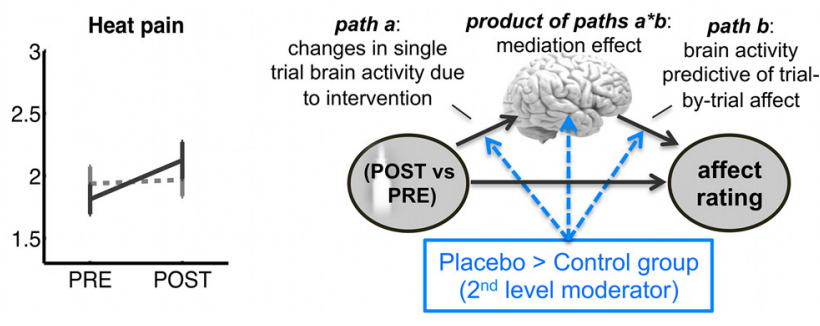

Figure 1. Study overview. A, Hypothetical and simplified brain network mediating placebo effects on affective states, adapted from current models of placebo effects on somatic pain. Placebo analgesia in somatic pain is mediated at least partially by the opioidergic descending pain modulatory system. dIPFC may represent treatment context and expectations, thereby modulating

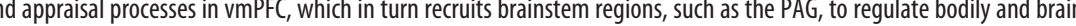
perimental task design. Participants performed the social rejection and heat pain tasks in separate runs (counterbalanced order) (Post) a Placebo or Control intervention. Each trial started with the presentation of a fixation cross, followed emotions associated with the respective event. They then had to rate how they felt on a $1-5$ Likert scale $(1=$ very bad; $5=$ very (hial structure, but instead of the pictures, included a $15 \mathrm{~s}$ painful (Heat) or nonpainful (Warm) thermal stimulation. mechanisms underlying these behavioral placebo effects, we used a multilevel mediation approach, with Postintervention versus Preintervention as a predictor, single-trial brain activity as mediator, and affect ratings as an outcome. Group (Placebo vs Control) was included as a second-level moderator, to investigate placebo-induced changes specifically.

questionnaire scores, and characteristics of the romantic relationship and breakup. Twenty additional participants were tested at a later time point and assigned to a distancing manipulation after baseline. Because of potential cohort effects, and to focus on placebo effects only, data from this additional group (Woo et al., 2014) are not reported here. All participants gave written informed consent and were paid for their time. The study was approved by the Institutional Review Board of Columbia University.

\section{Procedures}

Task design. All participants performed multiple separate runs that contained eight trials of either a social rejection task or a heat pain task (Fig. $1 B$ ), presented in counterbalanced order (Kross et al., 2011). Each trial in the social rejection task started with the presentation of a fixation cross for $7 \mathrm{~s}$. Then participants were presented with a photo of their ex-partner or a friend (15 s) and subsequently had to rate $(5 \mathrm{~s})$ how they felt using a 5 point scale $($ from $1=$ very bad to $5=$ very good $)$. Trials were separated by short epochs of a visuospatial control task to prevent carryover effects (Kross et al., 2011). The heat pain task had a parallel design, with either painful or nonpainful thermal stimulation administered to the left volar forearm for $15 \mathrm{~s}$, again followed by the participants' affect rating and the visuospatial control task. Affect, rather than pain intensity, was rated in both modalities to make them more comparable with each other. Past placebo studies have identified placebo effects on intensity, affect, or both, but they are often highly correlated under normative conditions $(r>0.9)$ (Wager et al., 2004). 
Stimuli. For the social rejection task, we collected headshot photographs of each participant's ex-partner (Ex-Partner condition) and of a same-gendered friend with whom they shared a positive experience during the time of the romantic relationship breakup (Friend condition). Further, cue phrases were presented beneath each photograph that directed participants to focus on reexperiencing the emotions associated with each of those events/persons (Kross et al., 2011). Thermal stimulation was applied using a TSA-II Neurosensory Analyzer (Medoc) with a $16 \mathrm{~mm}$ thermode endplate at individually calibrated temperatures, rated as either only mildly painful (Warm, 2 of 10 point scale) or painful (Heat pain, 8 of 10 point scale) (Kross et al., 2011).

Placebo intervention. Following the preintervention period, participants were randomly assigned to a Placebo or a Control group $(N=20$ each) and then performed again two runs of each task (Postintervention). All participants received a nasal spray containing saline solution, but with different instructions to evoke specific treatment expectations. In the Placebo condition, they were told that the nasal spray was a "powerful analgesic that is also effective in reducing emotional pain and negative affect." Participants in the Control condition were told that the spray contained a simple saline solution that was used to improve the contrast of the fMRI images but had otherwise no effects. We used a multilevel GLM to assess the effects of the intervention on single-trial affect ratings in the ExPartner (social) and Heat (physical pain) conditions.

\section{fMRI data acquisition and statistical analysis}

Acquisition and preprocessing. Functional imaging data were acquired using a GE 1.5T scanner covering the whole brain in 24 axial slices $(3.5 \times$ $3.5 \times 4.5 \mathrm{~mm}$ voxels $)$, with a $\mathrm{T}^{*}$-weighted spiral in-out sequence $(\mathrm{TR}=$ $2 \mathrm{~s}, \mathrm{TE}=40 \mathrm{~ms}$, flip angle $\left.=84^{\circ}, \mathrm{FOV}=22 \mathrm{~cm}\right)$. Preprocessing of functional images was performed with SPM8 (RRID: SCR_007037), using motion correction, slice-time correction, spatial normalization to MNI space, and spatial smoothing using a $8 \mathrm{~mm}$ FWHM Gaussian kernel. For spatial normalization, T1-spoiled, gradient-recalled structural images were first coregistered to the mean functional image and normalized to the SPM template using unified segmentation. Resulting images were sampled at $3 \times 3 \times 3 \mathrm{~mm}$ resolution.

Pattern expression. Previously, we identified two multivariate patterns trained on the preintervention phase alone, collapsing across Placebo and Control groups, which sensitively discriminated the Ex-Partner versus Friend conditions, and the Heat versus Warm conditions, respectively (Woo et al., 2014). These patterns provide a priori, rejection- and pain-related brain markers for testing placebo effects after intervention. Testing distributed patterns is advantageous, as research on emotion suggests that distributed representations are required to capture the processes that contribute to creating emotional experiences (Chang et al., 2015; Wager et al., 2015).

For this purpose, we first computed a GLM, including regressors for Friend, Ex-Partner, Warm, and Heat epochs. Additional regressors modeled the affect rating periods and the visuospatial control task. Movement parameters were added as regressors of no interest to control for motion artifacts and spikes. Contrast images were computed for each condition versus baseline, separately for Preintervention and Postintervention. We then calculated the cross-product (as a measure of pattern expression) of these individual contrast images (Ex-Partner Post and Pre, Heat Post and Pre) with the patterns trained to classify rejection and heat pain during the Preintervention epoch (Woo et al., 2014).

Multilevel mediation analysis. Based on previous work (Vogt et al., 1993; Mayberg et al., 2002; Petrovic et al., 2002; Bingel et al., 2006; Eippert et al., 2009; Hsu et al., 2013; Wager and Atlas, 2015), we tested whether placebo effects on social pain were mediated by dlPFC-PAG/ brainstem and vmPFC/OFC/rACC-PAG/brainstem pathways (Fig. 1A). We thus conducted a multilevel mediation model, described below, in these key regions. We focus here on prefrontal-brainstem pathways because they have been the most consistently involved in both placebo effects (Wager and Atlas, 2015) and opioid effects on pain and rejection (Fields et al., 2006; Hsu et al., 2013).

We first obtained single-trial $\beta$ estimates of rejection-related brain activity by including one regressor for each Friend, Ex-Partner, Warm, and Heat epoch to a GLM. Additional regressors again modeled the affect rating periods and the visuospatial control task, and movement parameters were added as regressors of no interest to control for motion artifacts and spikes. To avoid that single-trial estimates could be driven by movement artifacts or other noise, trial estimates with variance inflation factors $>5$ were excluded from further analysis (Atlas et al., 2010). We then tested relationships between Time (Post-treatment vs Pretreatment), single-trial brain activity, and affect ratings across individual trials using multilevel mediation analysis, with Group as a second-level (between-person) moderator (Kenny et al., 2003; Atlas et al., 2010) (Fig. $1 D)$. Multilevel mediation analysis identifies three steps in a potential mechanistic pathway underlying placebo effects: (1) brain regions that show activity increases or decreases during placebo (Path $a$ ), (2) brain regions that predict changes in affect (Path $b$ ), when controlled for Path $a$, and (3) brain regions that formally mediate the relationship between intervention and changes in affect (Path $a b$ ), which significantly reduce the strength of the direct Path $c^{\prime}$. Given that we aimed for functional changes due to placebo treatment specifically and to control for potential habituation or Time effects (i.e., Postintervention $>$ Preintervention), we included Group (Placebo $>$ Control) as a second-level moderator (placebo effects on Paths $a, b$, and $a b$ ). Resulting activation maps were thresholded at $p<0.05$ FDR (corresponding to a voxel threshold of $p<$ 0.00026 for social and $p<0.00014$ for physical pain) corrected across the whole brain and across mediation paths (Atlas et al., 2010). To facilitate interpretation of the functional maps, adjacent voxels were displayed at thresholds of $p<0.005$ and $p<0.05$ uncorrected. We focus the presentation of our results in a priori regions of interests: right dlPFC, PAG/ brainstem, and vmPFC/OFC/rACC (Fig. 1A). These regions of interest (ROIs) were derived from a previous meta-analysis (Meissner et al., 2011; Wager and Fields, 2013) at a more liberal threshold of 3 peaks within 15 $\mathrm{mm}$ for dlPFC and vmPFC/OFC/rACC, to cover not only meta-analytic peaks but also extended activations of prefrontal areas. The PAG/brainstem ROI was extracted at the original threshold of $10 \mathrm{~mm}$ to avoid extension into thalamic and cerebellar areas, which we did not hypothesize to play a central role in placebo effects. The PAG is a small structure, and this ROI includes other adjacent brainstem areas as well, such as parts of the superior colliculus and the dorsal raphe nucleus (Fig. 1A). To display the direction of the moderation effects, $\beta$ weights were extracted for significant clusters and plotted separately for both experimental groups. To explore the role of additional brain areas in addition to the ROIs, we present whole-brain results at the same FDR-corrected threshold $(p<0.05)$.

dlPFC pattern similarity analysis. To test whether mediation of placebo effects on social versus physical pain were driven by separable activation patterns in the dlPFC, we compared individual (person-level) images for the social pain mediation effect (Path $a b$ ) with images for the physical pain mediation effects for individuals in the Placebo group $(N=20)$. We trained a support vector machine (SVM) to classify to which modality (social or physical) each map belonged. To assess the accuracy of the classifier, we used a cross-validation procedure, in which the two mediation images for each subject served as a holdout set once, resulting in a 20 -fold (leave-one-subject out) cross-validation. Accuracy is reported on forced-choice tests on holdout (test) images. To test whether this pattern was indeed driven by the mediation of the placebo effects and not by residual activity due to rejection versus heat pain, we performed the same SVM analysis in the Control group as well.

\section{Results}

\section{Social rejection}

Behavioral results

We tested for placebo effects on reported rejection and pain experience using a multilevel GLM. In line with our prediction, placebo treatment reduced social pain, as evidenced by a significant effect of Placebo versus Control Group on Pretreatment versus Post-treatment negative affect $\left(t_{(38)}=3.3, p=0.001\right.$, Cohen's $d=1.04$ ). This effect is shown in Figure $1 C$. No significant changes were observed for the Friend condition. 
Placebo effects on an a priori fMRI marker of rejection

To test for placebo effects on the expression of the social rejection pattern (developed by Woo et al., 2014), as in previous studies (Wager et al., 2013), we calculated the cross-product of the social-rejection pattern (Woo et al., 2014) with the individual contrast images for the Ex-Partner condition Preintervention and Postintervention. This provided a single number for each participant that reflected the intensity of activation in the rejection pattern. We expected a reduction in the rejection signature with placebo. Paired $t$ tests between Placebo and Control groups revealed a greater decrease in rejection pattern expression in the Placebo compared with the Control group Postintervention compared with Preintervention $\left(t_{(19)}=2.2, p=0.022\right)$, due to a significantly lower pattern expression Postintervention in the Placebo compared with the Control group $\left(t_{(19)}=1.8, p=0.042\right)$.

\section{Placebo effects on}

prefrontal-brainstem pathways

Our moderated mediation model tests for placebo-induced changes (Post vs Pre) in brain activity (placebo effect on Path $a$ ) and in brain activity mediating the effect on behavioral outcomes (placebo effect on Path $a b$ ). It also tests whether the brain predictors of affect ratings varied significantly across groups (placebo effect on Path $b$ ), which would indicate placebo-induced changes in the relationships between brain activity and affective experience. Such changes could indicate recruitment of different local circuits within affective brain regions under placebo, possibly related to differences in the quality of cognitive appraisal.

The results of this analysis, testing mediation of placebo effects on social pain in three key regions, dlPFC, vmPFC/OFC/rACC, and PAG/brainstem, are shown in Figure 2. In line with our hypothesis, the right dIPFC showed significant effects for group differences on all three paths, in partially overlapping clusters (Fig. 2A). Following treatment, activity increased more in the Placebo compared with the Control group (placebo effect on Path $a$, peak coordinates $x=52, y=-4, z=46, Z=9.79$ ). Further, functional activity in right dlPFC was correlated with more positive affect ratings in the Placebo group, but not in the Control group (placebo effect on Path $b, x=32, y=2, z=50$, $Z=9.19$ ). This indicates that placebo treatment altered the functional relationship between activity and affective outcomes, and specifically that the contents of activated dIPFC representations were more strongly associated with positive affect under Placebo. Several clusters in right dIPFC also showed significant group differences in mediation effects (placebo effect on Path $a b, x=44$, $y=0, z=34, Z=8.91$ ), confirming a key role of this region in mediating placebo treatment effects on behavioral outcomes.
The vmPFC/OFC/rACC (Fig. $2 B$ ) showed clusters of moderated Path $a$ and moderated Path $b$ effects, but no mediation effects. Activity in vmPFC/medial OFC increased from Pretreatment to Post-treatment more in the Placebo than in the Control group (placebo effect on Path $a, x=-14, y=40, z=-20, Z=$ 7.12). Activity in adjacent subgenual rACC correlated positively with affect in the Placebo, but not the Control group (placebo effect on Path $b, x=-12, y=30, z=-14, Z=12.66$ ).

Finally, a placebo effect on Path $b$ effect was found in the PAG and adjacent brainstem areas (Fig. 2C; $x=0, y=-30, z=-16$, $Z=11.49$ ), indicating again a strong positive relationship between activity in this region and affect in the Placebo group, but a negative relationship between activity and affect in the Control group. Interestingly, although activity in the PAG/brainstem was strongly correlated with affect ratings (placebo effect on Path $b$ ), it was not strongly enough affected by the placebo manipulation to reach significance (placebo effect on Path $a$ ).

Our additional, exploratory whole-brain analysis (Fig. 3) showed the involvement of further regions in placebo effects on social pain. Most notably, parts of the insula were more positively predictive for 


\section{A Post $>$ Pre treatment in Placebo $>$ Control group} (placebo effect on Path a)
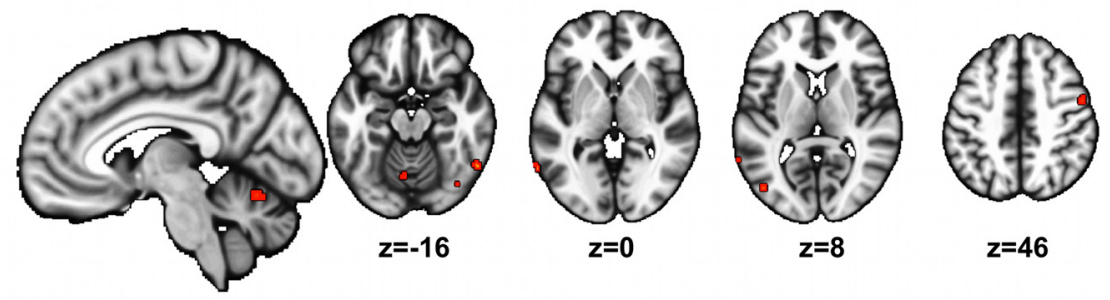

B Activity predictive of improved affect in Placebo > Control group (placebo effect on Path b)
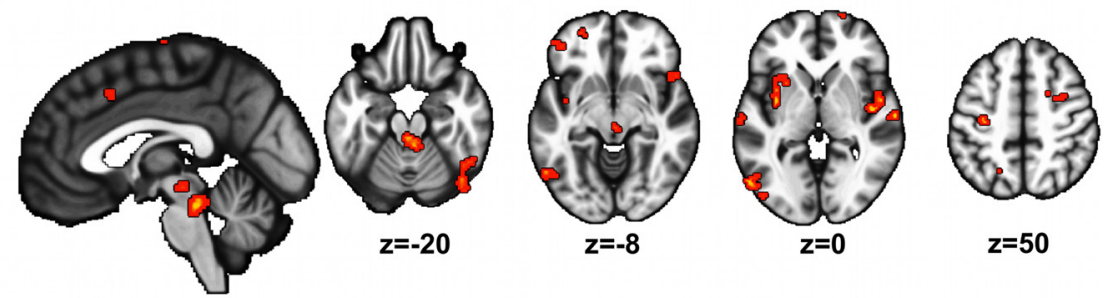

\section{Significant mediators of Placebo > Control treatment on affect (placebo effect on Path ab)}
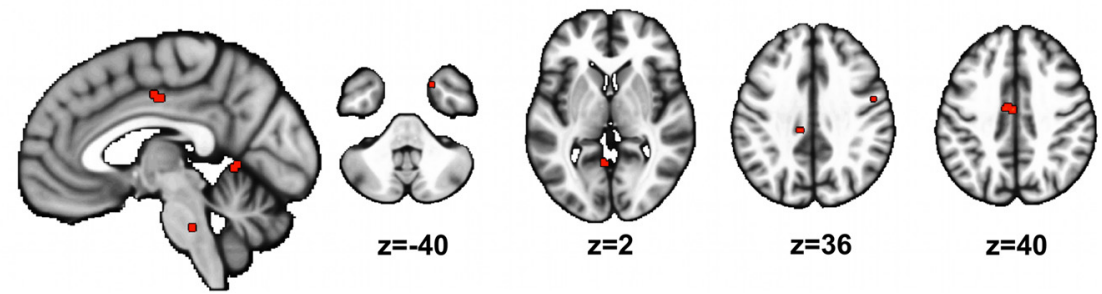

Figure 3. Exploratory whole-brain analysis of placebo treatment effects on social pain. $\boldsymbol{A}$, Moderated Path $a$ effect, illustrating activity increases Post-treatment $>$ Pretreatment in the Placebo $>$ Control group. $\boldsymbol{B}$, Moderated Path $b$ effect, indicating changes in the relationship between activity and affect in the Placebo compared with the Control group. C, Moderated Path $a b$ effect, showing formal mediation effects in the Placebo $>$ Control group. All results thresholded at $p<0.05$, FDR corrected.

smaller clusters in the left ventral part of the middle frontal gyrus and the right postcentral gyrus were not theoretically predicted (Fig. 4B). Thus, the right dlPFC partially mediates the effects of the placebo intervention on PAG/brainstem responses, which in turn predicts reduced negative affect specifically in the Placebo group.

\section{Heat pain}

Behavioral results

Placebo treatment also reduced negative affect ratings during heat pain, as indicated by a Group $\times$ Time effect $\left(t_{(38)}=\right.$ $1.92, p=0.031$, Cohen's $d=0.61$; Fig. $1 C)$, yet this effect was less strong than in the social pain condition and only driven by a group differences in slopes. Although not predicted, a similar placebo-related improvement was observed in the Warm (control) condition, Group $\times$ Time effect $\left(t_{(38)}\right.$ $=3.12, p=0.002$ ). These results were less strong than those for social pain but are consistent with those observed in many other studies of pain. We therefore expected that brain findings may be statistically weaker but might yield some parallels with social pain nonetheless.

Expression of an a priori fMRI marker of heat pain

In parallel to our analyses of social rejection, we tested whether the multivariate marker trained to classify pain Preintervention (Woo et al., 2014) was attenuated during placebo. However, in contrast to the results for rejection, we did not observe a significant difference in pattern expression decrease on the heat pain

affect in the placebo compared with the control group (Path $b$, Fig. $3 B$ ). Parts of the vlPFC and dACC showed similar Path $b$ effects (Fig. $3 B)$. Strong Path $a$ and $b$ effects were further found in bilateral dlPFC and dorsal parietal areas (Fig. $3 A, B$ ), in agreement with previous findings (e.g., Wager et al., 2004, 2011). Mediation effects (Path $a b$; Fig. 3C) were most prominent in right dlPFC, brainstem, and posterior cingulate cortex.

Based on our theoretical model of placebo effects on social pain (Fig. 1A), we next tested whether the regulatory role of the PAG/ brainstem was driven by top-down input from the vmPFC/OFC/ rACC, the dlPFC, or another brain region. Activity in frontal regions may represent treatment expectations that could recruit descending opioidergic pathways and thereby influence the regulatory role of brainstem areas, such as the PAG (Vogt et al., 1993; Petrovic et al., 2002; Bingel et al., 2006; Eippert et al., 2009; Büchel et al., 2014; Wager and Atlas, 2015; Koban et al., 2017). Thus, we conducted a three-path mediation analysis (Taylor et al., 2007; Woo et al., 2015) in the Placebo group, searching to identify brain regions that (1) respond to placebo treatment and (2) influence affect ratings via PAG/brainstem activity (Fig. 4A). The results of this whole-brain analysis showed a significant three-path mediation effect in a cluster in the right dIPFC $(x=23, y=15, z=47$; Fig. $4 B)$, which overlapped in location with the dlPFC ROI and with the Path $a$ and $a b$ effects shown above, indicating an important role of prefrontal-PAG/ brainstem functional pathways in placebo effects on social pain. Two contrast images between groups after the intervention $(p=$ 0.652). Similarly, pattern expression of the Neurophysiological Pain Signature (Wager et al., 2013) did not show a significantly different decrease $(p=0.266)$.

\section{Multilevel mediation analysis}

We next investigated whether functional activity in the three key ROIs mediated placebo effects on changes in somatic pain. As with social pain, we found that activity in right dlPFC was increased Postintervention compared with Preintervention, specifically in the Placebo, but not in the Control group (placebo effect on Path $a$; Fig. $5 A$, peak coordinates $x=52, y=8, z=34, Z=$ $10.85)$. In addition, activity in dlPFC was positively correlated with improved affect (thus, less pain) in the Placebo group, but not in the Control group (placebo effect on Path $b, x=50, y=$ $-2, z=36, Z=12.54)$. Finally, activity in dlPFC formally mediated treatment effects on affect in the Placebo, but not the Control group (placebo effect on Path $a b, x=36, y=2, z=36, Z=$ 9.56). Mediation effects were also found in one cluster in the vmPFC/OFC/rACC (Fig. 5B; $x=10, y=40, z=-10, Z=6.18$ ), but not in the PAG/brainstem (Fig. $5 C$ ).

An additional, exploratory whole-brain analysis (Fig. 6) revealed additional increased activation in right posterior parietal activations (Path $a$; Fig. 6A). Path $b$ effects were found in several areas, including bilateral posterior parietal and posterior cingu- 


\section{A Three-path mediation model}

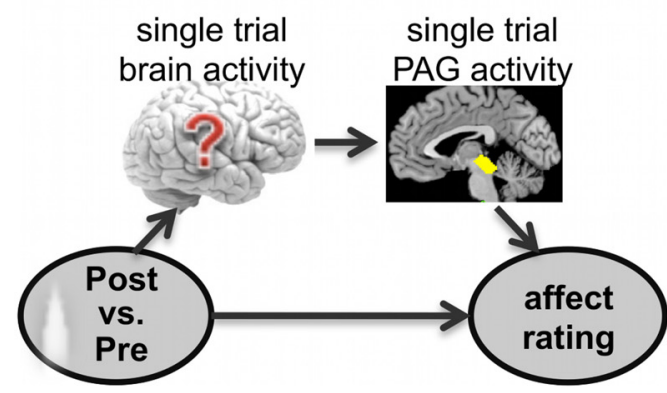

\section{B Results}

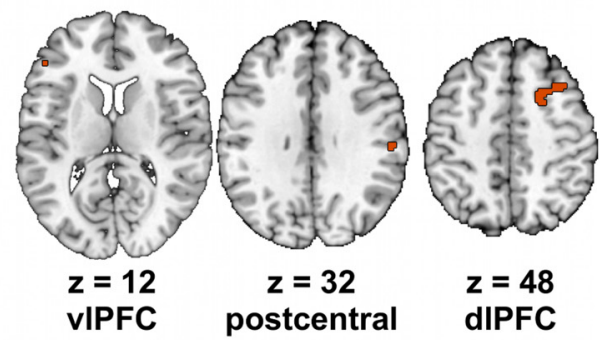

Figure 4. Three-path mediation model of placebo effects on social rejection-related pain. $A$, Based on current models of placebo effects, we searched the whole brain for regions that would mediate the effect of placebo treatment on PAG, which in turn would directly influence social rejection-related pain (affect ratings). $\boldsymbol{B}$, The results of this analysis revealed clusters in the right dIPFC, alongside with left vIPFC, and right postcentral sulcus, which showed significant three-path mediation effects (thresholded for display at $p<0.01$, peak voxels of each cluster were significant at $p<0.05$, FDR corrected).

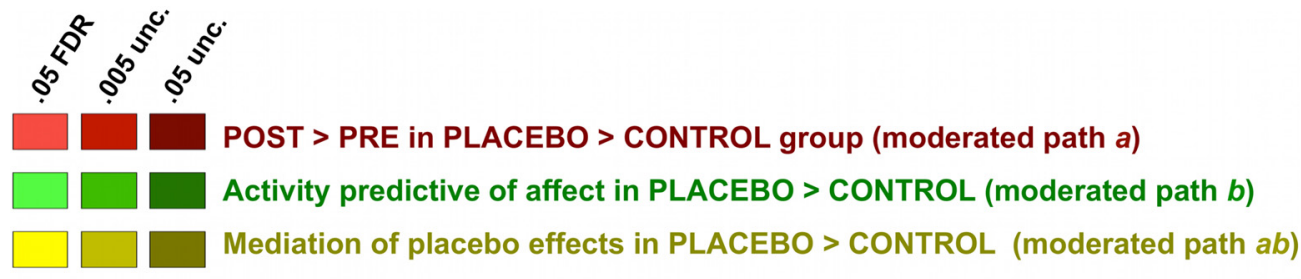

\section{A Placebo effects on heat pain: right dIPFC}
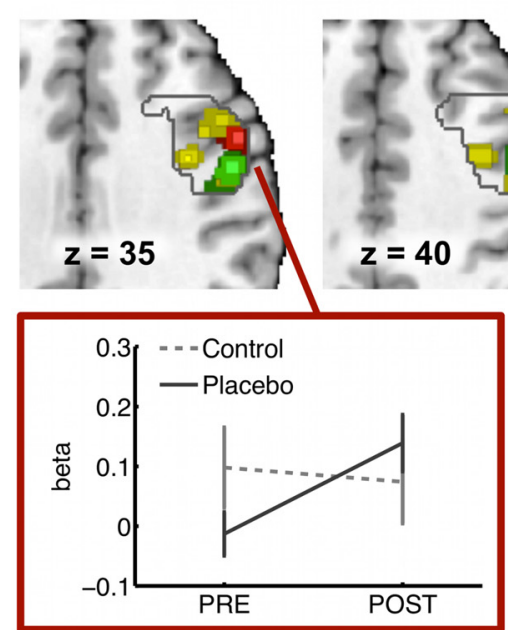

B vmPFC/OFC/rACC

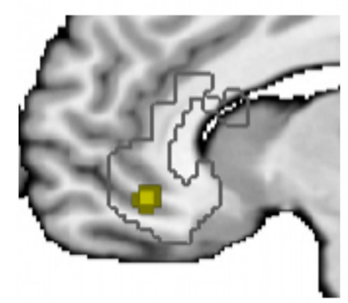

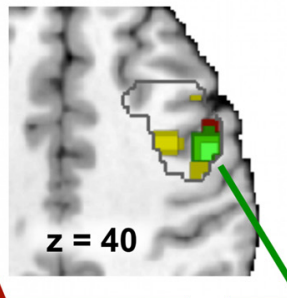
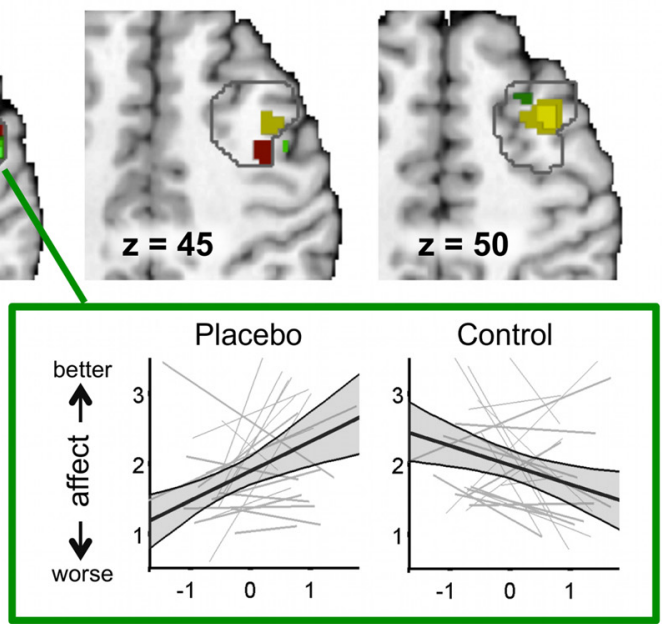

C Brainstem/PAG

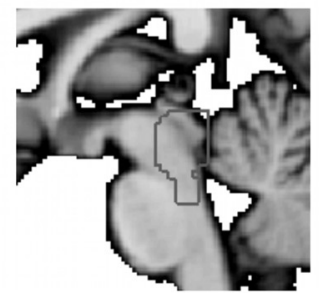

Figure 5. Mediation of placebo treatment effects on heat pain in key regions. $\boldsymbol{A}$, Right dIPFC. $\boldsymbol{B}, \mathrm{vmPFC} / \mathrm{OFC} / \mathrm{rACC}$. C, PAG and brainstem. Gray outlines in brain plots indicate ROIs (see also Fig. $1 A$ ). Red represents group differences in changes in brain activity to Heat pain Post versus Pre placebo treatment (placebo effect on Path $a$ ). Box with red borders represents the direction of these intervention effects. Error bars indicate SEM. Plots with green borders represent placebo effects on Path $b$ effects (green), depicting individual regression lines for the relationship between single-trial brain activity and affect ratings in the Placebo (left) and the Control (right) group. Whereas activity in the right dIPFC was predictive of more positive affect in the Placebo group, it correlated negatively with affect ratings in the Control group, similar to the findings regarding social rejection. Yellow represents brain activity formally mediating the relationship between placebo treatment and changes in affect (placebo effect on Path $a b$ ) (right dIPFC and vmPFC/OFC/rACC). 


\section{A Post $>$ Pre treatment in Placebo $>$ Control group (placebo effect on Path a)}
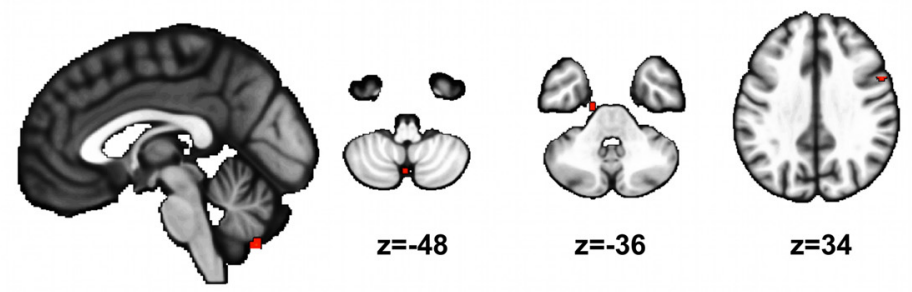

\section{B Activity predictive of improved affect in Placebo > Control group (placebo effect on Path $b$ )}
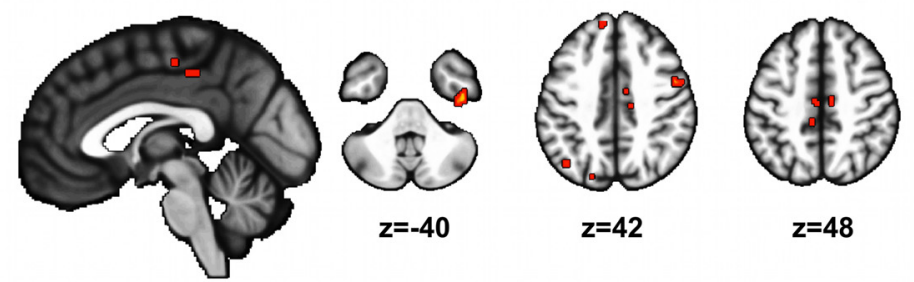

\section{Significant mediators of Placebo $>$ Control treatment on affect (placebo effect on Path ab)}
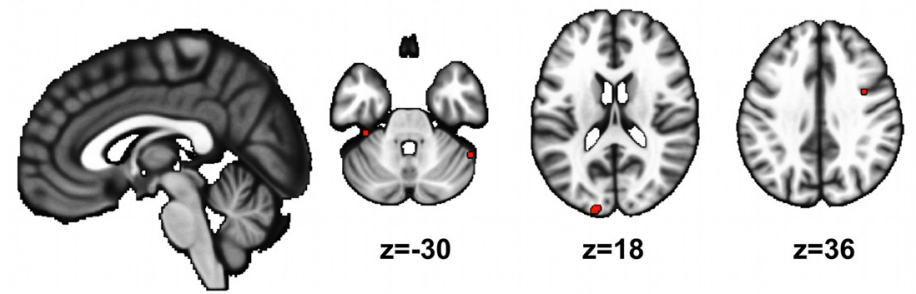

Figure 6. Exploratory whole-brain analysis of placebo treatment effects on physical heat pain. $\boldsymbol{A}$, Moderated Path $a$ effect, illustrating activity increases Post-treatment $>$ Pretreatment in the Placebo $>$ Control group. $\boldsymbol{B}$, Moderated Path $b$ effect, indicating changes in the relationship between activity and affect in the Placebo compared with the Control group. $\boldsymbol{C}$, Moderated Path $a b$ effect, showing formal mediation effects in the Placebo $>$ Control group. All results thresholded at $p<0.05$, FDR corrected.

late cortex (Fig. 6B). Finally, mediation effects were found in dorsolateral prefrontal and posterior parietal areas, in addition to subgenual cingulate, occipital cortex, and basal ganglia (Fig. 6C).

\section{Comparison of social and heat pain placebo effects}

Activity in the right dlPFC mediated placebo effects on both physical and social pain, but there was very little direct overlap in the activated clusters (Figs. 2, 5). On one hand, these might reflect activation of the same underlying representation, albeit with spatial noise; placebo effects have been shown to transfer from pain to negative emotion (Zhang and Luo, 2009) and empathy (Rütgen et al., 2015), suggesting similarity. On the other hand, representations in the dlPFC-mediating placebo effects in these two modalities might be different; for example, placebo effects have often found to be uncorrelated across domains (Liberman, 1964; Koban et al., 2013) and even unrelated after minor changes in placebo instructions (Whalley et al., 2008).

We therefore trained a SVM classifier to separate the mediationrelated (Path $a b$ ) patterns for social and physical pain in the right dlPFC. The classifier (Fig. 7) was able to discriminate whether individual participants' mediation effect maps were related to physical or social pain with $80 \%$ accuracy $( \pm 8.9 \%$ SE, forced-choice test within subjects, $p=0.012$ ) in the Placebo, but not the Control group (performance at chance). This
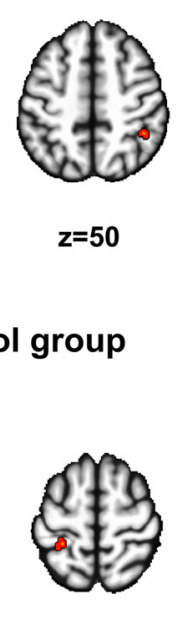

$z=60$

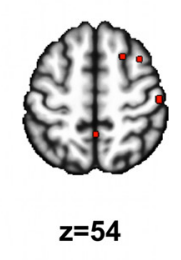

finding implies that patterns of placeboinduced dIPFC activity in physical and social pain are each conserved across individuals to some degree but are reliably different from one another (Fig. 7).

\section{Discussion}

Placebo treatments affect outcomes across multiple disorders and conditions (Benedetti, 2008). Whereas common brain mechanisms in the regulation of pain and other affective states have been hypothesized ( $\mathrm{Zu}-$ bieta et al., 2003; Ellingsen et al., 2013; Hsu et al., 2013), those have seldom been directly compared (Ellingsen et al., 2013; Rütgen et al., 2015). The present study investigated, for the first time, placebo effects on social rejection-related "pain" and their neural underpinnings, and compared them with a more established placebo effect, placebo analgesia, in the same subjects. We found that a placebo nasal spray caused substantial reductions in rejection-related negative affect and modest reductions in physical pain. This behavioral effect was paralleled by a decrease in the response of a recently developed multivariate social rejection-specific pattern (Woo et al., 2014).

Our comparisons of brain mechanisms mediating placebo effects on social and physical pain focused on established prefrontal-brainstem pathways. Similar to placebo effects on physical heat pain, the right dlPFC and vmPFC/OFC/rACC showed placebo-induced increases in activity during social pain. This is in line with previous studies showing involvement of these prefrontal regions in placebo effects on pain (Petrovic et al., 2002, 2010; Bingel et al., 2006; Eippert et al., 2009; Krummenacher et al., 2010; Koban et al., 2012; Amanzio et al., 2013; Geuter et al., 2013; Wager and Atlas, 2015) and treatment effects on Parkinson's disease, depression, anxiety, and negative affective stimuli (Mayberg et al., 2002; Petrovic et al., 2005; Benedetti, 2008; Schmidt et al., 2014).

Our analysis framework represents a relatively novel approach to investigating placebo effects. We used mediation analysis to model neurophysiological pathways, going beyond effects on single regions and relating connectivity to behavioral placebo effects. Based on previous research and theoretical models of placebo analgesia (Petrovic et al., 2002; Benedetti et al., 2011; Büchel et al., 2014; Wager and Atlas, 2015; Koban et al., 2017), we tested the hypothesis that functional interactions between prefrontal cortex (especially dlPFC and vmPFC/OFC/rACC) and the PAG would mediate placebo effects on social pain (Fig. 4). This extends previous work showing placebo-induced enhancement of medial prefrontal-PAG connectivity (Bingel et al., 2006; Wager et al., 2007; Eippert et al., 2009) by linking activity directly to experimentally induced variations in emotional experience. These pathways have previously been studied chiefly in relation to physical pain (Vogt et al., 1993; Tracey, 2010; Büchel et al., 2014; Wager and Atlas, 2015). Previous work manipulating 


\section{A Classification}

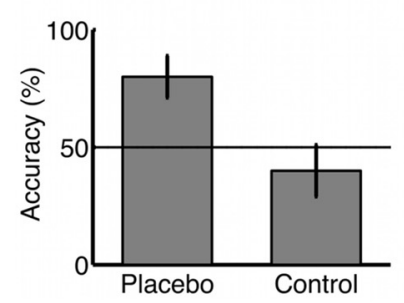

B SVM classifier weights in the dIPFC (Placebo)

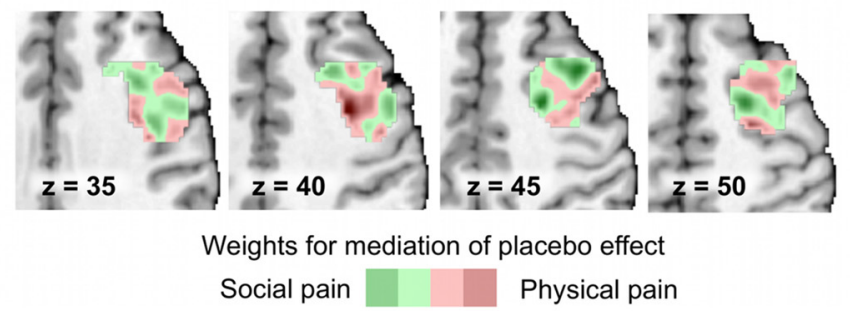

Figure 7. Separable mediation of placebo effects on physical and social pain in the dIPFC. $\boldsymbol{A}$, The multivariate classifier of dIPFC activity was able to accurately classify mediation effects of social versus physical pain placebo effects in the Placebo ( $80 \%$ cross-validated accuracy), but not in the Control group (40\%). Error bars indicate SEM. $\boldsymbol{B}$, Voxel weights of the classifier in the Placebo group. Pale green represents weights toward social pain placebo mediation. Pink represets weights toward physical pain placebo effects.

dlPFC has been shown to causally affect pain experience (Taylor et al., 2013) and effects of placebo (Benedetti et al., 2006; Krummenacher et al., 2010). dlPFC and PAG are part of a larger opioidergic "descending pain modulatory system" (Fields, 2004; Gebhart, 2004), and recent work implicates the opioid system and PAG also in other types of affect (Panksepp, 1998; Keay and Bandler, 2001; Zubieta et al., 2003; Ribeiro et al., 2005; Linnman et al., 2012; Buhle et al., 2013), including social pain and separation (Herman and Panksepp, 1978; Way et al., 2009; Panksepp, 2011; Hsu et al., 2013). Potentially due to statistical power issues, $\mathrm{vmPFC/OFC/rACC}$ were not identified as direct mediators of $\mathrm{PAG}$ effects but are likely to have an important role in regulating PAG as well.

Furthermore, our analyses also allowed us to test two different types of functional relationships between brain activity, placebo, and affect that have not previously been examined. In a "fixed affect" modal model, the relationship between brain activity and emotional experience is constant. Placebo treatment increases activity in prefrontal and brainstem areas, which in turn downregulate regions associated with negative affect. However, such a "fixed affect" model is less compatible with the observation that brain areas, such as the PAG, are involved in both positive and negative affective states and their regulation. Alternatively, in a "context-dependent affect" model, different contextual states, such as placebo treatment, may shift the relationship between brain activity and emotional experience. This is likely to occur if emotions depend on the contents of thoughts encoded in brain appraisal systems: Activity could support positive or negative outcomes depending on the nature of the appraisal (Kim and Hamann, 2007; Wager et al., 2008; Urry et al., 2009; Buhle et al., 2014). This is consistent with both appraisal (Scherer, 1999; Brosch and Sander, 2013) and constructionist models of emotion (Barrett, 2006; Lindquist et al., 2012), and predicts nonlinear interactions between brain, placebo, and negative emotional intensity.

Strikingly, our results most strongly support the second view. Under the control treatment, dlPFC, vmPFC/OFC/rACC, and $\mathrm{PAG}$ activities were all associated with more negative affect. After Placebo treatment, activity in each of these regions was associated with reduced negative affect. Similar effects were found in other cortical regions associated with affect and arousal, including insula and dACC. These findings are consistent with the idea that placebo treatment alters affective appraisals in these circuits, inducing a shift in the relationship between brain activity and affect. This does not preclude findings supporting the "fixed affect" model; indeed, we do find placebo-induced increases in dlPFC and reductions in the multivariate social pain pattern, but it demonstrates how moving beyond fixed views of brain-affect relationships is important for understanding placebo effects and related phenomena.
Together, these findings provide part of the foundation for a working model of placebo effects across affective states (Fig. 1A) (Koban et al., 2017). Prefrontal regions maintain necessary context information and attentional set (Benedetti et al., 2006; Krummenacher et al., 2010; Koban et al., 2017), and /rACC /OFC (with an associated striatal network) maintains information about current expected value (Roy et al., 2014), which is compared with PAG-mediated information about aversive outcomes to shape avoidance over time (Roy et al., 2014). Placebo treatments interface with this system via prefrontal regulation of PAG and likely other forebrain and brainstem regions (Vogt et al., 1993; Petrovic et al., 2002; Zubieta and Stohler, 2009; Büchel et al., 2014; Wager and Atlas, 2015). And, whereas most previous analyses have assumed that PAG representations do not change with context, PAG may play a more dynamic role in appraisal, increasing or reducing negative affect depending on context and prefrontal input. The functions of these systems may not be limited to negative affect. For example, a recent study (Ellingsen et al., 2013) compared placebo analgesia and placebo hyperhedonia (increased pleasure), suggesting that enhanced PAG-vmPFC coupling can downregulate or upregulate sensory processing, depending on its emotional value, to meet expectations of benefit (Ellingsen et al., 2013).

\section{Implications for shared mechanisms of social and physical pain}

Our findings are in line with the idea that some broad regulatory mechanisms, especially prefrontal-brainstem interactions, are shared in placebo effects across different conditions. A recent study has shown naloxone-reversible transfer effects from placebo effects on physical pain to those on empathy (Rütgen et al., 2015), suggesting common opioidergic regulation of pain and empathy. Whereas Rütgen et al. (2015) studied observation of others in pain, here we focused on feelings of rejection, which have a different neural basis (Krishnan et al., 2016). In addition, that previous study did not investigate the regulatory network (e.g., prefrontal systems) and brain connectivity mediating placebo effects. The present findings therefore complement those earlier results by showing placebo-related activity and mediation effects in dlPFC on rejection, a strong and unique emotional experience relevant for well-being.

The present results also provide strong evidence for dissimilarity. Our multivariate analysis revealed that the activation patterns in the dlPFC-mediating placebo effects are modalityspecific. An SVM classifier was able to reliably separate local spatial patterns in mediation maps (Path $a^{\star} b$ maps of Placebo $\rightarrow$ Brain $\rightarrow$ Affect) for social and physical pain. This classification result was stable across individuals, demonstrating that the placebo effect-mediating patterns in dlPFC are preserved 
across persons within each modality but are different across modalities. This suggests that placebo-relevant representations (e.g., of expectations) and top-down regulation of brain activity by dIPFC during social and physical pain are distinct, despite potentially parallel mechanisms at a broad spatial scale.

\section{Limitations and future directions}

Although we focused on specific prefrontal-PAG pathways, there is evidence that a broader network of regions is important for placebo effects. In our additional whole-brain analyses, insula, ACC, vlPFC, parietal areas, and OFC increased during placebo or were positively predictive of affect ratings. The importance of these regions is also supported by previous placebo studies (Mayberg et al., 2002; Petrovic et al., 2010; Geuter et al., 2013) and by studies on cognitive emotion-regulation (especially vlPFC) (Wager et al., 2008). Interestingly, most of these regions have direct connections to brainstem structures, such as the PAG (Benarroch, 2012), and are also rich in opioid receptors (Baumgärtner et al., 2006), and may be related to social pain (Hsu et al., 2013). Future studies could complement our focused approach by investigating the role of these other regions in the regulation of social and physical pain, as well as other affective states.

In addition, several other limitations should be mentioned. First, to compare placebo effects on physical and social pain, both modalities were tested; however, the results revealed a somewhat less powerful placebo effect in the physical pain condition (in both behavior and brain). Our comparisons here do not depend on matching the strength of placebo responses, although future studies could provide more quantitative comparisons if they are able to do so. Second, we found a decrease in the response of the rejection-specific brain pattern (Woo et al., 2014), indicating that our placebo intervention altered the neurophysiological processing of the social rejection condition. However, it has to be noted that this pattern was not trained to track intensity differences in social rejection, but to separate social rejection-related pain from physical pain (Woo et al., 2014). Therefore, future studies might develop and use intensity-sensitive patterns tracking the experience of social rejection, in combination with hormonal and physiological measures of emotional distress. Third, we do not provide direct evidence on opioid involvement here, although other studies support a role for opioids (Wager et al., 2007; Scott et al., 2008; Eippert et al., 2009; Hsu et al., 2013; Peciña et al., 2015; Rütgen et al., 2015). PET imaging or pharmacological manipulations could be used to test specific hypothesis regarding the role of the opioidergic system in the placebo-induced regulation of social rejection-related pain.

\section{References}

Amanzio M, Benedetti F, Porro CA, Palermo S, Cauda F (2013) Activation likelihood estimation meta-analysis of brain correlates of placebo analgesia in human experimental pain. Hum Brain Mapp 34:738-752. CrossRef Medline

Atlas LY, Bolger N, Lindquist MA, Wager TD (2010) Brain mediators of predictive cue effects on perceived pain. J Neurosci 30:12964-12977. CrossRef Medline

Barrett LF (2006) Are emotions natural kinds? Perspect Psychol Sci 1:2858. CrossRef Medline

Baumgärtner U, Buchholz HG, Bellosevich A, Magerl W, Siessmeier T, Rolke R, Höhnemann S, Piel M, Rösch F, Wester HJ, Henriksen G, Stoeter P, Bartenstein P, Treede RD, Schreckenberger M (2006) High opiate receptor binding potential in the human lateral pain system. Neuroimage 30:692-699. CrossRef Medline

Benarroch EE (2012) Periaqueductal gray: an interface for behavioral control. Neurology 78:210-217. CrossRef Medline

Benedetti F (2008) Mechanisms of placebo and placebo-related effects across diseases and treatments. Annu Rev Pharmacol Toxicol 48:33-60. CrossRef Medline

Benedetti F, Arduino C, Amanzio M (1999) Somatotopic activation of opioid systems by target-directed expectations of analgesia. J Neurosci 19: 3639-3648. Medline

Benedetti F, Arduino C, Costa S, Vighetti S, Tarenzi L, Rainero I, Asteggiano G (2006) Loss of expectation-related mechanisms in Alzheimer's disease makes analgesic therapies less effective. Pain 121:133-144. CrossRef Medline

Benedetti F, Carlino E, Pollo A (2011) How placebos change the patient's brain. Neuropsychopharmacology 36:339-354. CrossRef Medline

Bingel U, Lorenz J, Schoell E, Weiller C, Büchel C (2006) Mechanisms of placebo analgesia: $\mathrm{rACC}$ recruitment of a subcortical antinociceptive network. Pain 120:8-15. CrossRef Medline

Bingel U, Schoell E, Büchel C (2007) Imaging pain modulation in health and disease. Curr Opin Neurol 20:424-431. CrossRef Medline

Brosch T, Sander D (2013) Comment: the appraising brain: towards a neuro-cognitive model of appraisal processes in emotion. Emotion Rev 5:163-168. CrossRef

Büchel C, Geuter S, Sprenger C, Eippert F (2014) Placebo analgesia: a predictive coding perspective. Neuron 81:1223-1239. CrossRef Medline

Buhle JT, Kober H, Ochsner KN, Mende-Siedlecki P, Weber J, Hughes BL, Kross E, Atlas LY, McRae K, Wager TD (2013) Common representation of pain and negative emotion in the midbrain periaqueductal gray. Soc Cogn Affect Neurosci 8:609-616. CrossRef Medline

Buhle JT, Silvers JA, Wager TD, Lopez R, Onyemekwu C, Kober H, Weber J, Ochsner KN (2014) Cognitive reappraisal of emotion: a meta-analysis of human neuroimaging studies. Cereb Cortex 24:2981-2990. CrossRef Medline

Chang LJ, Gianaros PJ, Manuck SB, Krishnan A, Wager TD (2015) A sensitive and specific neural signature for picture-induced negative affect. PLoS Biol 13:e1002180. CrossRef Medline

Chen Z, Williams KD, Fitness J, Newton NC (2008) When hurt will not heal: exploring the capacity to relive social and physical pain. Psychol Sci 19: 789-795. CrossRef Medline

Eippert F, Bingel U, Schoell ED, Yacubian J, Klinger R, Lorenz J, Büchel C (2009) Activation of the opioidergic descending pain control system underlies placebo analgesia. Neuron 63:533-543. CrossRef Medline

Eisenberger NI, Cole SW (2012) Social neuroscience and health: neurophysiological mechanisms linking social ties with physical health. Nat Neurosci 15:669-674. CrossRef Medline

Ellingsen DM, Wessberg J, Eikemo M, Liljencrantz J, Endestad T, Olausson H, Leknes S (2013) Placebo improves pleasure and pain through opposite modulation of sensory processing. Proc Natl Acad Sci U S A 110:1799317998. CrossRef Medline

Fields H (2004) State-dependent opioid control of pain. Nat Rev Neurosci 5:565-575. CrossRef Medline

Fields HL, Basbaum AI, Heinricher MM (2006) Central nervous system mechanisms of pain modulation. In: Textbook of pain, Ed 5 (McMahon SB, Koltzenburg M, eds), pp 125-142. London: Elsevier.

Flaten MA, Aslaksen PM, Lyby PS, Bjørkedal E (2011) The relation of emotions to placebo responses. Philos Trans R Soc Lond B Biol Sci 366:1818 1827. CrossRef Medline

Gebhart GF (2004) Descending modulation of pain. Neurosci Biobehav Rev 27:729-737. CrossRef Medline

Geuter S, Eippert F, Hindi Attar C, Büchel C (2013) Cortical and subcortical responses to high and low effective placebo treatments. Neuroimage 67: 227-236. CrossRef Medline

Herman BH, Panksepp J (1978) Effects of morphine and naloxone on separation distress and approach attachment: evidence for opiate mediation of social affect. Pharmacol Biochem Behav 9:213-220. CrossRef Medline

Hsu DT, Sanford BJ, Meyers KK, Love TM, Hazlett KE, Wang H, Ni L, Walker SJ, Mickey BJ, Korycinski ST, Koeppe RA, Crocker JK, Langenecker SA, Zubieta JK (2013) Response of the $\mu$-opioid system to social rejection and acceptance. Mol Psychiatry 18:1211-1217. CrossRef Medline

Keay KA, Bandler R (2001) Parallel circuits mediating distinct emotional coping reactions to different types of stress. Neurosci Biobehav Rev 25: 669-678. CrossRef Medline

Kenny DA, Korchmaros JD, Bolger N (2003) Lower level mediation in multilevel models. Psychol Methods 8:115-128. CrossRef Medline

Kim SH, Hamann S (2007) Neural correlates of positive and negative emotion regulation. J Cogn Neurosci 19:776-798. CrossRef Medline 
Kirsch I, Sapirstein G (1998) Listening to Prozac but hearing placebo: a meta-analysis of antidepressant medication. Prevention Treatment 1 .

Koban L, Brass M, Lynn MT, Pourtois G (2012) Placebo analgesia affects brain correlates of error processing. PLoS One 7:e49784. CrossRef Medline

Koban L, Ruzic L, Wager TD (2013) Brain predictors of individual differences in placebo responding. In: Placebo and pain (Luana C, Magne Arve F, Meissner K, eds), pp 89-102. San Diego: Academic.

Koban L, Jepma M, Geuter S, Wager TD (2017) What's in a word? How instructions, suggestions, and social information change pain and emotion. Neurosci Biobehav Rev. Advance online publication. doi:10. 1016/j.neubiorev.2017.02.014.

Krishnan A, Woo CW, Chang LJ, Ruzic L, Gu X, López-Solà M, Jackson PL, Pujol J, Fan J, Wager TD (2016) Somatic and vicarious pain are represented by dissociable multivariate brain patterns. Elife 5:e15166. CrossRef Medline

Kross E, Egner T, Ochsner K, Hirsch J, Downey G (2007) Neural dynamics of rejection sensitivity. J Cogn Neurosci 19:945-956. CrossRef Medline

Kross E, Berman MG, Mischel W, Smith EE, Wager TD (2011) Social rejection shares somatosensory representations with physical pain. Proc Natl Acad Sci U S A 108:6270-6275. CrossRef Medline

Krummenacher P, Candia V, Folkers G, Schedlowski M, Schönbächler G (2010) Prefrontal cortex modulates placebo analgesia. Pain 148:368374. CrossRef Medline

Leuchter AF, Cook IA, Witte EA, Morgan M, Abrams M (2002) Changes in brain function of depressed subjects during treatment with placebo. Am J Psychiatry 159:122-129. CrossRef Medline

Liberman R (1964) An experimental study of the placebo response under three different situations of pain. J Psychiatr Res 2:233-246. CrossRef Medline

Lindquist KA, Wager TD, Kober H, Bliss-Moreau E, Barrett LF (2012) The brain basis of emotion: a meta-analytic review. Behav Brain Sci 35:121143. CrossRef Medline

Linnman C, Moulton EA, Barmettler G, Becerra L, Borsook D (2012) Neuroimaging of the periaqueductal gray: state of the field. Neuroimage 60 : 505-522. CrossRef Medline

Mayberg HS, Silva JA, Brannan SK, Tekell JL, Mahurin RK, McGinnis S, Jerabek PA (2002) The functional neuroanatomy of the placebo effect. Am J Psychiatry 159:728-737. CrossRef Medline

Meissner K, Bingel U, Colloca L, Wager TD, Watson A, Flaten MA (2011) The placebo effect: advances from different methodological approaches. J Neurosci 31:16117-16124. CrossRef Medline

Meyer B, Yuen KS, Ertl M, Polomac N, Mulert C, Büchel C, Kalisch R (2015) Neural mechanisms of placebo anxiolysis. J Neurosci 35:7365-7373. CrossRef Medline

Murphy ML, Slavich GM, Chen E, Miller GE (2015) Targeted rejection predicts decreased anti-inflammatory gene expression and increased symptom severity in youth with asthma. Psychol Sci 26:111-121. CrossRef Medline

Panksepp J (1998) Affective neuroscience: the foundations of human and animal emotions. Oxford: Oxford UP.

Panksepp J (2011) The neurobiology of social loss in animals: some keys to the puzzle of psychic pain in humans. In: Social pain: neuropsychological and health implications of loss and exclusion. (MacDonald G, JensenCampbell LA, eds), pp 11-51. Washington DC: American Psychological Association.

Panksepp J, Herman BH, Vilberg T, Bishop P, DeEskinazi FG (1980) Endogenous opioids and social behavior. Neurosci Biobehav Rev 4:473487. CrossRef Medline

Peciña M, Bohnert AS, Sikora M, Avery ET, Langenecker SA, Mickey BJ, Zubieta JK (2015) Association between placebo-activated neural systems and antidepressant responses: neurochemistry of placebo effects in major depression. JAMA Psychiatry 72:1087-1094. CrossRef Medline

Petrovic P, Kalso E, Petersson KM, Ingvar M (2002) Placebo and opioid analgesia: imaging a shared neuronal network. Science 295:1737-1740. CrossRef Medline

Petrovic P, Dietrich T, Fransson P, Andersson J, Carlsson K, Ingvar M (2005) Placebo in emotional processing, induced expectations of anxiety relief activate a generalized modulatory network. Neuron 46:957-969. CrossRef Medline

Petrovic P, Kalso E, Petersson KM, Andersson J, Fransson P, Ingvar M (2010) A prefrontal non-opioid mechanism in placebo analgesia. Pain 150:5965. CrossRef Medline
Plassmann H, O’Doherty J, Shiv B, Rangel A (2008) Marketing actions can modulate neural representations of experienced pleasantness. Proc Natl Acad Sci U S A 105:1050-1054. CrossRef Medline

Price DD, Finniss DG, Benedetti F (2008) A comprehensive review of the placebo effect: recent advances and current thought. Annu Rev Psychol 59:565-590. CrossRef Medline

Ribeiro SC, Kennedy SE, Smith YR, Stohler CS, Zubieta JK (2005) Interface of physical and emotional stress regulation through the endogenous opioid system and $\mu$-opioid receptors. Prog Neuropsychopharmacol Biol Psychiatry 29:1264-1280. CrossRef Medline

Roy M, Shohamy D, Daw N, Jepma M, Wimmer GE, Wager TD (2014) Representation of aversive prediction errors in the human periaqueductal gray. Nat Neurosci 17:1607-1612. CrossRef Medline

Rütgen M, Seidel EM, Silani G, Riečanský I, Hummer A, Windischberger C, Petrovic P, Lamm C (2015) Placebo analgesia and its opioidergic regulation suggest that empathy for pain is grounded in self pain. Proc Natl Acad Sci U S A 112:E5638-E5646. CrossRef Medline

Scherer KR (1999) Appraisal theory. In: Handbook of cognition and emotion (Dalgleish T, Power MJ, eds), pp 637-663. New York: John Wiley \& Sons.

Schienle A, Übel S, Schöngaßner F, Ille R, Scharmüller W (2014) Disgust regulation via placebo: an fMRI study. Soc Cogn Affect Neurosci 9:985990. CrossRef Medline

Schmidt L, Braun EK, Wager TD, Shohamy D (2014) Mind matters: placebo enhances reward learning in Parkinson's disease. Nat Neurosci 17:17931797. CrossRef Medline

Scott DJ, Stohler CS, Egnatuk CM, Wang H, Koeppe RA, Zubieta JK (2008) Placebo and nocebo effects are defined by opposite opioid and dopaminergic responses. Arch Gen Psychiatry 65:220-231. CrossRef Medline

Slavich GM, O'Donovan A, Epel ES, Kemeny ME (2010) Black sheep get the blues: a psychobiological model of social rejection and depression. Neurosci Biobehav Rev 35:39-45. CrossRef Medline

Taylor AB, MacKinnon DP, Tein YT (2007) Tests of the three-path mediated effect. Organizational Res Methods 11:241-269.

Taylor JJ, Borckardt JJ, Canterberry M, Li X, Hanlon CA, Brown TR, George MS (2013) Naloxone-reversible modulation of pain circuitry by left prefrontal rTMS. Neuropsychopharmacology 38:1189-1197. CrossRef Medline

Tracey I (2010) Getting the pain you expect: mechanisms of placebo, nocebo and reappraisal effects in humans. Nat Med 16:1277-1283. CrossRef Medline

Urry HL, van Reekum CM, Johnstone T, Davidson RJ (2009) Individual differences in some (but not all) medial prefrontal regions reflect cognitive demand while regulating unpleasant emotion. Neuroimage 47:852863. CrossRef Medline

Vogt BA, Sikes RW, Vogt LJ (1993) Anterior cingulate cortex and the medial pain system. In: Neurobiology of cingulate cortex and limbic thalamus, pp 313-344. New York: Springer.

Wager TD, Atlas LY (2015) The neuroscience of placebo effects: connecting context, learning and health. Nat Rev Neurosci 16:403-418. CrossRef Medline

Wager TD, Fields H (2013) Placebo analgesia. In: Wall \& Melzack's textbook of pain (McMahon SB, Koltzenburg M, Tracey I, Turk DC, eds), pp 362-373. Philadelphia, PA: Elsevier Health Sciences.

Wager TD, Rilling JK, Smith EE, Sokolik A, Casey KL, Davidson RJ, Kosslyn SM, Rose RM, Cohen JD (2004) Placebo-induced changes in FMRI in the anticipation and experience of pain. Science 303:1162-1167. CrossRef Medline

Wager TD, Scott DJ, Zubieta JK (2007) Placebo effects on human $\mu$-opioid activity during pain. Proc Natl Acad Sci U S A 104:11056-11061. CrossRef Medline

Wager TD, Davidson ML, Hughes BL, Lindquist MA, Ochsner KN (2008) Prefrontal-subcortical pathways mediating successful emotion regulation. Neuron 59:1037-1050. CrossRef Medline

Wager TD, Atlas LY, Leotti LA, Rilling JK (2011) Predicting individual differences in placebo analgesia: contributions of brain activity during anticipation and pain experience. J Neurosci 31:439-452. CrossRef Medline

Wager TD, Atlas LY, Lindquist MA, Roy M, Woo CW, Kross E (2013) An fMRI-based neurologic signature of physical pain. N Engl J Med 368: 1388-1397. CrossRef Medline

Wager TD, Kang J, Johnson TD, Nichols TE, Satpute AB, Barrett LF (2015) A Bayesian model of category-specific emotional brain responses. PLoS Comput Biol 11:e1004066. CrossRef Medline

Way BM, Taylor SE, Eisenberger NI (2009) Variation in the $\mu$-opioid recep- 
tor gene (OPRM1) is associated with dispositional and neural sensitivity to social rejection. Proc Natl Acad Sci U S A 106:15079-15084. CrossRef Medline

Weimer K, Colloca L, Enck P (2015) Placebo effects in psychiatry: mediators and moderators. Lancet Psychiatry 2:246-257. CrossRef Medline

Whalley B, Hyland ME, Kirsch I (2008) Consistency of the placebo effect. J Psychosom Res 64:537-541. CrossRef Medline

Woo CW, Koban L, Kross E, Lindquist MA, Banich MT, Ruzic L, AndrewsHanna JR, Wager TD (2014) Separate neural representations for physical pain and social rejection. Nat Commun 5:5380. CrossRef Medline

Woo CW, Roy M, Buhle JT, Wager TD (2015) Distinct brain systems mediate the effects of nociceptive input and self-regulation on pain. PLoS Biol 13:e1002036. CrossRef Medline
Zhang W, Luo J (2009) The transferable placebo effect from pain to emotion: changes in behavior and EEG activity. Psychophysiology 46:626634. CrossRef Medline

Zhang YQ, Tang JS, Yuan B, Jia H (1997) Inhibitory effects of electrically evoked activation of ventrolateral orbital cortex on the tail-flick reflex are mediated by periaqueductal gray in rats. Pain 72:127-135. CrossRef Medline

Zubieta JK, Stohler CS (2009) Neurobiological mechanisms of placebo responses. Ann N Y Acad Sci 1156:198-210. CrossRef Medline

Zubieta JK, Ketter TA, Bueller JA, Xu Y, Kilbourn MR, Young EA, Koeppe RA (2003) Regulation of human affective responses by anterior cingulate and limbic $\mu$-opioid neurotransmission. Arch Gen Psychiatry 60:11451153. CrossRef Medline 